\title{
Petroleum Geological Analysis Based on Remote Sensing and laser scanning in Karamay Formation of Junggar Basin, China
}

\author{
Qihong Zeng ${ }^{1}$, Youyan Zhang ${ }^{1}$, Linghua Kong ${ }^{2}$, Yong Ye ${ }^{1}$, Yan Hu ${ }^{1}$, Wenzhi Wang ${ }^{1}$ and Yuanyuan Chen ${ }^{3 *}$ \\ ${ }^{1}$ Research Institute of Petroleum Exploration\&Development, Petro China, Beijing,100083, China \\ ${ }^{2}$ Research Institute of Exploration and Development, Xinjiang Oilfield Company, PetroChina, Karamay, Xinjiang, 834000, China \\ ${ }^{3}$ University of Science and Technology LiaoNing, Anshan,114051, China
}

\begin{abstract}
This paper uses high-precision remote sensing and laser scanning to study petroleum geological analysis methods. The research area is Karamay Formation in Junggar Basin, China. Firstly, the outcrop lithologies are identified according to our clastic rock lithology identification pattern based on laser intensity, and the regional lithologies are identified based on high-precision remote sensing images. Furthermore, we analyze the horizontal and vertical distribution characteristics of the sandbodies. At last, we analyze the area sandbody connectivity and sandbody structure characteristics. These data can provide basic information for the analysis of underground reservoirs in Karamay Formation.
\end{abstract}

\section{Introduction}

Digital outcrop is an effective method to realize the research of underground reservoir analogues. The digital outcrop based on remote sensing and ground laser scanning can study the outcrop reservoir structure intuitively, quantitatively and precisely .

Lidar can quickly and accurately obtain the 3D information of the measured object, and establish a digital outcrop model of the geological body. There are literatures that are currently studying the extraction of effective geological information based on lidar data and digital models[1-3]. Zeng et al.[4-5] studied the extraction of geological information from a digital outcrop based on lidar, and Zhu et al.[6] developed sedimentary reservoirs based on digital outcrop technology, Zheng et al.[7] studied the application of digital outcrop in reservoir geological modeling. Sheng et al.[8] realized the estimation method of sandstone outcrop porosity based on hyperspectral; some abroad scholars have used laser intensity to explore lithology identification[9].

In this paper, high-precision remote sensing and lidar technology are used to establish the digital outcrop model of the Karamay Formation in Shendigou area of the Junggar Basin. Combined with the ground geological survey, the lithology identification and quantitative characterization are carried out, and the structural characteristics of the surface sandbodies of the Karamay Formation are analyzed to provide basic data for reservoir analysis.

\section{Geological background of the study area}

The Karamay Formation and Baikouquan Formation of the Triassic strata in the northwestern margin of the Junggar Basin are the main productive layers, mainly with coarse clastic deposits. In this paper, the Karamay Formation outcrops exposed in Shendigou area are used as the research area to analyze the distribution characteristics of sandbodies. The outcrop of Shendigou area is $2000 \mathrm{~m} \times 800 \mathrm{~m}$ (Fig. 1), and there are strata such as Carboniferous, Triassic, and Jurassic. The Triassic strata are missing the Lower Triassic The Baikouquan Formation (T1b). The Middle Triassic Karamay Formation(T2k) is divided into the Lower Karamay Formation (T2k1) and the Upper Karamay Formation (T2k2).

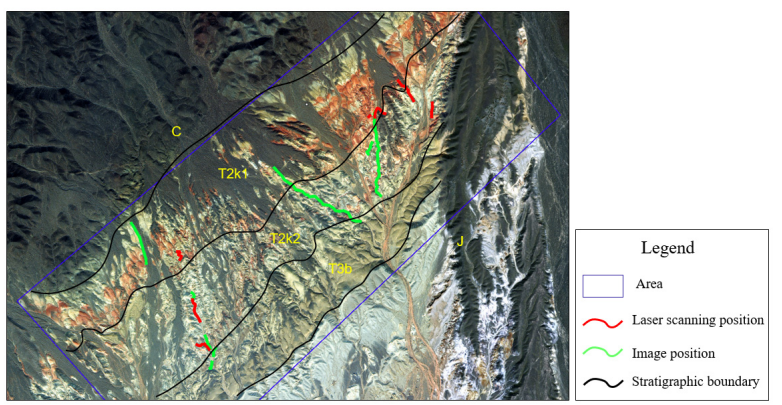

Fig. 1. The outcrop research area.

\section{Lithology identification}

The lithology identification in this paper is divided into two parts, outcrop lithology identification and regional 
lithology identification. Based on lidar scanning local outcrop, using laser intensity data combined with highprecision photos to identify lithology from outcrop. The regional lithology is identified based on high-precision remote sensing image. Then we can obtain quantitative data of reservoir parameters and analyze the distribution characteristics of the reservoir.

\subsection{Outcrop lithology identification}

Based on laser scanning to obtain 3D information of geological outcrop, a high-precision digital outcrop model can be established. In the model, the laser intensity combined with high-precision photos can be used to explain the lithological changes of the outcrop and obtain quantitative parameter information.

According to the analysis of laser scanning experiment of clastic rock samples including four types of rock types: medium conglomerate, fine conglomerate, sandstone, siltstone and mudstone, the laser intensity values of different rock types have obviously distributing rules. The clastic rock lithology identification pattern based on laser intensity is as fig.2. The greater the particle size, the greater the intensity value. The experimental results show that the average laser intensity of medium conglomerate is $-1.33 \mathrm{db}$, the average laser intensity of fine conglomerate is $-2.07 \mathrm{db}$, the average of laser intensity of sandstone is $-4.87 \mathrm{db}$, and the average value of laser intensity of siltstone is $-6.01 \mathrm{db}$, the average value of laser intensity of mudstone is $-7.10 \mathrm{db}$.

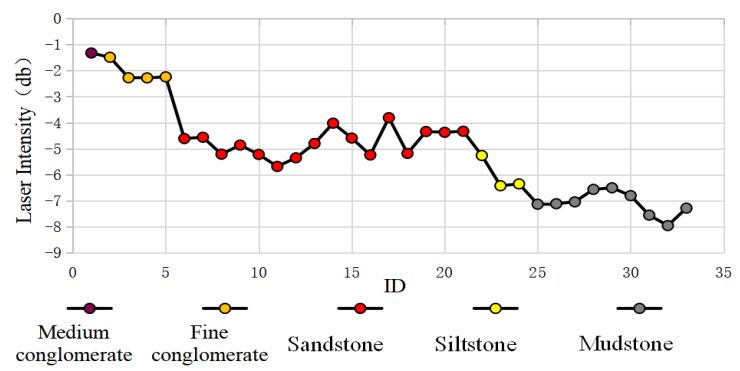

Fig. 2. The clastic rock lithology identification pattern based on laser intensity.

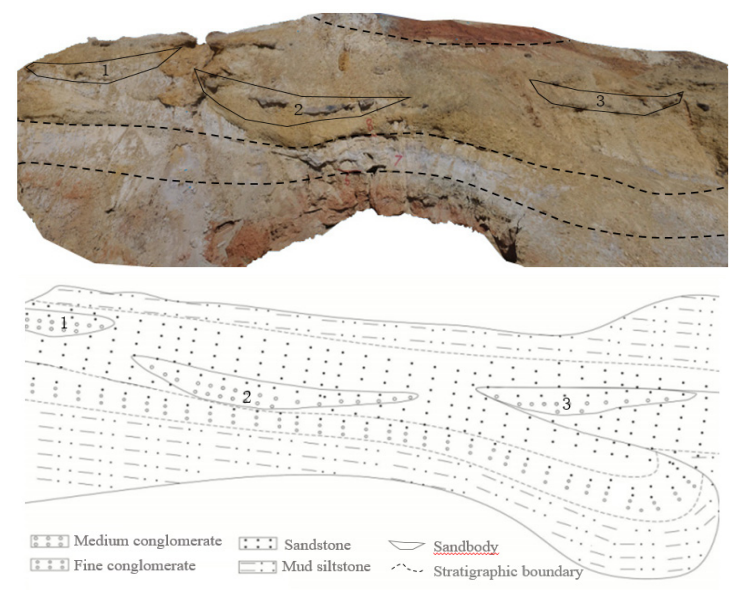

Fig. 3. Digital outcrop model and lithology interpretation.

Combining the above average laser intensity and texture photos of different lithologies, the digital outcrop model in Fig. 3 is interpreted. The outcrop is mainly conglomerate, fine conglomerate, sandstone and muddy siltstone. The width of the body is about $6 \mathrm{~m}$, the thickness of the sand body is $1 \sim 2 \mathrm{~m}$, and the width-tothickness ratio is relatively stable (Table1).

Table 1. Sandbody width-thickness ratio.

\begin{tabular}{|c|c|c|c|}
\hline No. & Width $(\mathrm{m})$ & Thickness $(\mathrm{m})$ & $\begin{array}{c}\text { Width- } \\
\text { thickness ratio }\end{array}$ \\
\hline 1 & $6.1 \mathrm{~m}$ & $1.3 \mathrm{~m}$ & 4.7 \\
\hline 2 & $6.8 \mathrm{~m}$ & $1.6 \mathrm{~m}$ & 4.3 \\
\hline 3 & $6.2 \mathrm{~m}$ & $1.2 \mathrm{~m}$ & 5.2 \\
\hline
\end{tabular}

\subsection{Regional lithology identification}

High-precision remote sensing image texture color information can accurately identify lithology in the region. Using the lithology identification results of the digital outcrop model as a calibration, a lithology identification mark is established on the corresponding remote sensing image. Then a human-machine interactive interpretation is performed on the corresponding remote sensing image in the study area in combination with the field geological survey to realize regional lithology identification. The results of the local remote sensing planar lithology identification of the Karamay Formation are shown in Fig.4, which mainly include conglomerate, sandstone, silty mudstone and mudstone.

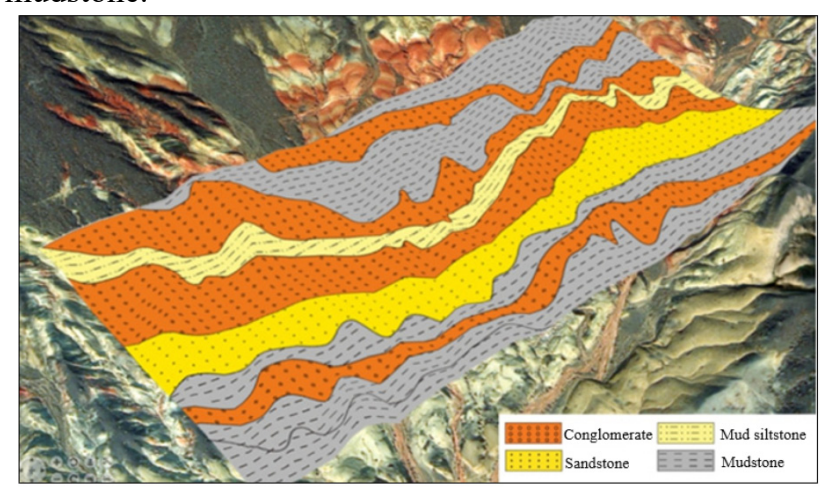

Fig. 4. Regional Remote Sensing Planar Lithology Distribution.

\section{Sandbody characteristics analysis}

Based on the identification of lithology, the distribution characteristics of sandstone and conglomerate and the connection relationship of sandbody are quantitatively analyzied, so as to understand the underground reservoir structure.

\subsection{Sandbody distribution characteristics}

In the study area, the sandbody distribution characteristics of 4 profiles were studied in detail. Taking profile 1 as an example, the remote sensing highprecision digital elevation model (DEM) data is used to obtain true surface relief, and the quantitative information such as formation thickness and formation occurrence is accurately calculated. Then the horizontal 
and vertical lithology distribution section is drawn (Fig. 5). And the quantitative parameters of the sandbodies in profile 1 are analyzed in detail (Table 2).

The figure shows that the entire Karamay Formation is a depositional process from alluvial fan to fan delta, and the lithological assemblage presents the characteristics of positive cycle with lower coarseness and upper fineness, and the overall grain size of sandy conglomerate is $0.2 \sim 5 \mathrm{~cm}$. The lithology of the Lower Karamay Formation(T2k1) is mainly gray gravel and purple mudstone, which are alluvial fan deposits. Three to four sets of sand layers are developed in T2k1 Formation and one layer is $2 \mathrm{~m}$ thick conglomerate with a maximum gravel particle size of $8 \mathrm{~cm}$. The upper Karamay Formation(T2k2) is mainly composed of gray, gray-green sandstone and conglomerate, and maroon mudstone. It is a fan delta deposit with three to four sets of sand layers. Quartz particles are sub-circular.

\subsection{Regional sandbody connectivity}

The connection diagram of the vertical sandbodies of the 4 sections is shown in Fig. 6, and the quantitative parameters of the sandbodies are analyzed in detail (Table 3). The results of Table 2 show that: the thickness of the T2k1 Formation of conglomerate rock accounts for $40 \%$ of the total stratum thickness, of which the profile 2 sandstone ratio is $50 \%$. The thickness of the T2k2 Formation of gravel rock accounts for $54 \%$ of the total stratum thickness, of which the profile 2 sandstone ratio reaches $63 \%$. The thickness of the stratum conglomerate in the 4 sections accounted for $43 \%$ of the total stratum thickness.

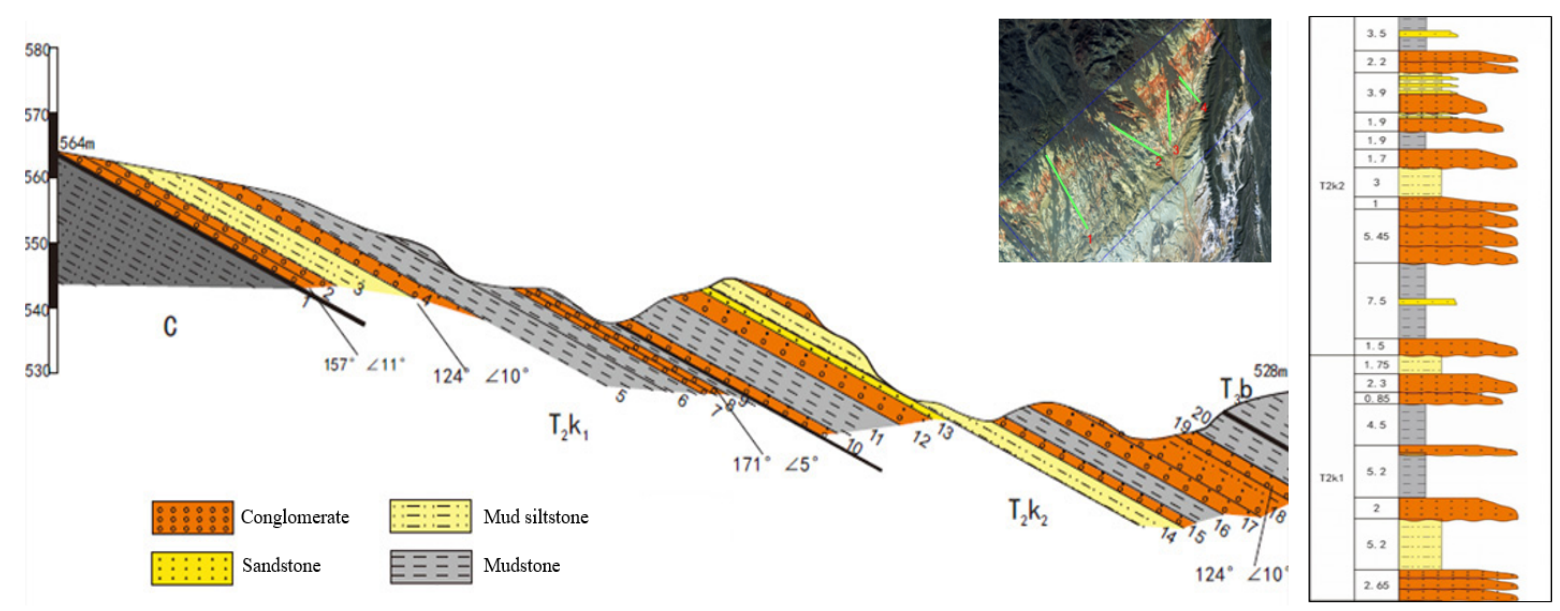

Fig. 5. The horizontal and vertical lithology distribution section.

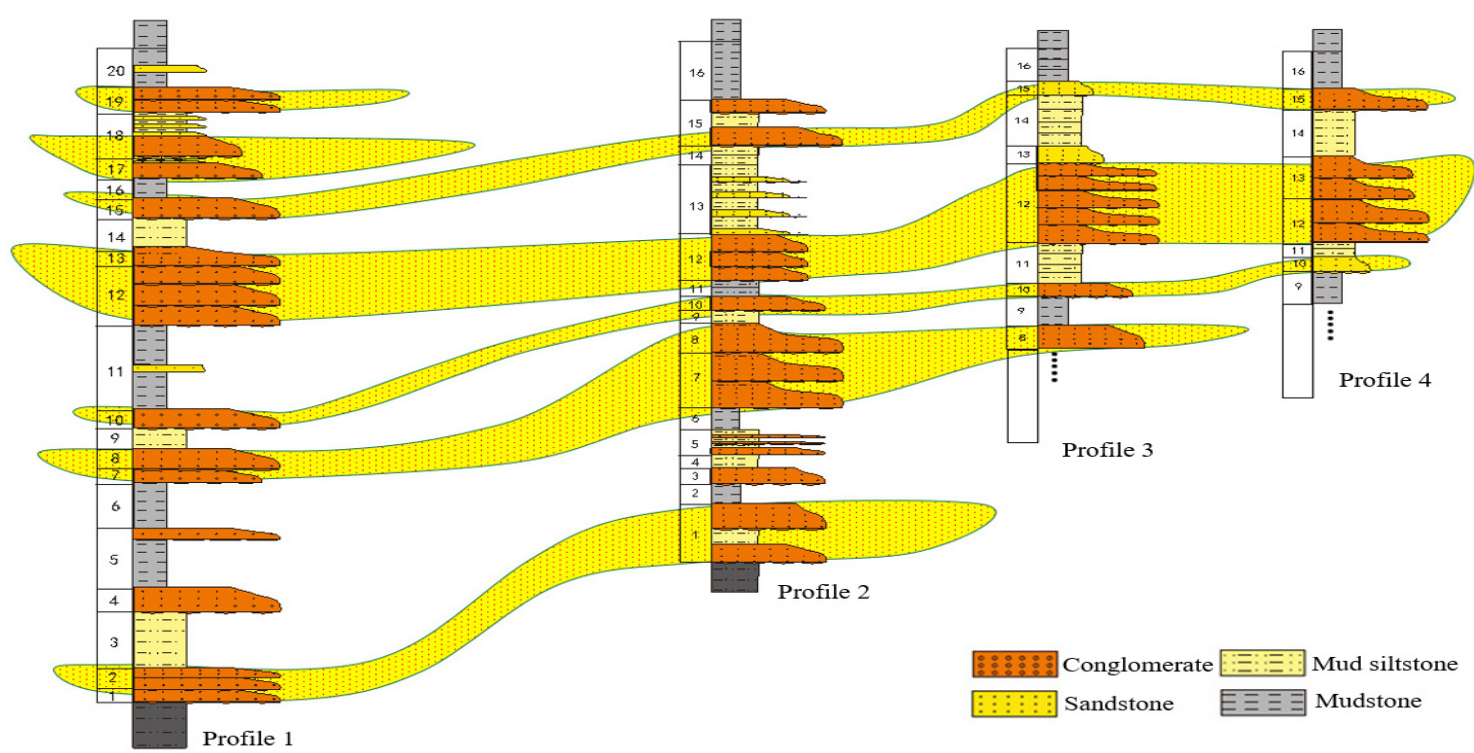

Fig. 6. The Vertical sandbody connectivity diagram.

Table 2. Profile 1 sandbody parameters.

\begin{tabular}{|c|c|c|c|c|}
\hline Lithology & $\begin{array}{c}\text { Number of } \\
\text { layers }\end{array}$ & $\begin{array}{c}\text { Total of thickness } \\
(\mathrm{m})\end{array}$ & $\begin{array}{c}\text { Minimum thickness } \\
(\mathrm{m})\end{array}$ & $\begin{array}{c}\text { Maximum thickness } \\
(\mathrm{m})\end{array}$ \\
\hline Conglomerate & 10 & 20.7 & 1 & 5.45 \\
\hline
\end{tabular}




\begin{tabular}{|c|c|c|c|c|}
\hline Sandstone & 2 & 4.75 & 0.85 & 3.9 \\
\hline Mud siltstone & 3 & 9.95 & 1.75 & 5.2 \\
\hline Mudstone & 5 & 22.6 & 1.9 & 7.5 \\
\hline
\end{tabular}

Table 3. Sandbody parameters.

\begin{tabular}{|c|c|c|c|c|c|c|}
\hline No. & $\begin{array}{c}\text { T2k2 Layer } \\
\text { Thickness }(\mathrm{m})\end{array}$ & $\begin{array}{c}\text { T2k2 Sand } \\
\text { Thickness }(\mathrm{m})\end{array}$ & $\begin{array}{c}\text { T2k2 Sand } \\
\text { Ratio(\%) }\end{array}$ & $\begin{array}{c}\text { T2k1 Layer } \\
\text { Thickness(m) }\end{array}$ & $\begin{array}{c}\text { T2k1 Sand } \\
\text { Thickness }(\mathrm{m})\end{array}$ & $\begin{array}{c}\text { T2k1 Sand } \\
\text { Ratio(\%) }\end{array}$ \\
\hline Profile 1 & 33.35 & 17.65 & 0.53 & 24.45 & 7.80 & 0.32 \\
\hline Profile 2 & 24.70 & 15.50 & 0.63 & 24.70 & 15.50 & 0.63 \\
\hline Profile 3 & 18.60 & 8.20 & 0.44 & 18.60 & 8.20 & 0.44 \\
\hline Profile 4 & 12.70 & 6.70 & 0.53 & 12.70 & 6.70 & 0.53 \\
\hline Average & 89.35 & 48.05 & 0.54 & 42.85 & 17.00 & 0.40 \\
\hline
\end{tabular}

\section{Conclusion}

In this paper, the lithology identification method and sandbody distribution analysis method are studied in combination with remote sensing and lidar. The sandbody of Karamay Formation in the Shendigou area of Junggar Basin is studied. The sandbodies are relatively connected, and the sandbodies present a positive cycle in the vertical direction. This method has good application prospects for fine geology research in oil and gas exploration.

\section{Acknowledgments}

The project was supported by National Science and Technology Major Projects (2017ZX05001001) and the Company Projects (kt2018-10-9).

\section{References}

1. Bellian, J.A., Kerans, C. and Jennette, D.C. Digital outcrop models: applications of terrestrial scanning lidar technology in stratigraphic modeling[J]. Journal of Sedimentary Research, 2005, 75(2):166176.

2. Enge, H.D., Buckley S.J., Rotevatn A., \& Howell J.A. From outcrop to reservoir simulation model: workflow and procedures[C]. Geosphere 2007, 3(6):469-490.

3. Hodgetts, D. Laser scanning and digital outcrop geology in the petroleum industry: A review[J]. MARINE AND PETROLEUM GEOLOGY, 2013, 46: $335-354$.

4. Zeng Qihong, Xie Xing, Zhang Youyan, et al. Digital Outcrop Modeling and Geology Information Extraction based on ground-based Lidar[C]. ICALIP 2012:580-583.
5. Zeng Qihong, Ma Yiyun, Xie Xing, et al. A study on surface modeling method of Digital Outcrop of Yanchang Formation, Ordos Basin[J]. Lithologic Reservoir,2015,27(5):1-5.

6. Zhu, R. K., B. Bai, X. J. Yuan, et al. A new approach for outcrop characterization and geostatistical analysis of meandering channels sandbodies within a delta plain setting using digital outcrop models: Upper triassic yanchang tight sandstone formation, yanhe outcrop, ordos basin: Acta Sedimentologica Sinica, 2013(31):867-877.

7. Jianfeng Zheng, Anjiang Shen, Zhanfeng Qiao, et al. LIDAR-based 3-D Digital Outcrop Modeling and Application in Geologic Modeling:A Case of Modeling of Middle Ordovician Reef-beach Carbonate Body at Dabantage Outcrop in Bachu Uplift, Tarim Basin[J]. Marine Origin Petroleum Geology, 3(19) , 2014:72-78.

8. Sheng Jie, Liu Zhan, Zeng Qihong, et al. Porosity Estimation method in sandstone outcrop based on hyperspectrum $[\mathrm{J}]$. Journal of Infrared and Millimeter Waves, 2018,37(6):779-788.

9. FRANCHESCHI, M., TEZA, G., PRETO, N., etc, Discrimination between marls and limestones using intensity data from terrestrial laser scanner, Journal of Photogrammetry and Remote Sensing. 2009.64:522-528. 